\title{
Genetic assemblage of Sarcocystis spp. in Malaysian snakes
}

\author{
Yee Ling Lau ${ }^{1 *}$, Phooi Yee Chang ${ }^{1 \dagger}$, Vellayan Subramaniam², Yit Han $\mathrm{Ng}^{1}$, Rohela Mahmud ${ }^{1}$, \\ Arine Fadzlun Ahmad ${ }^{1}$ and Mun Yik Fong ${ }^{1}$
}

\begin{abstract}
Background: Sarcocystis species are protozoan parasites with a wide host range including snakes. Although there were several reports of Sarcocytis species in snakes, their distribution and prevalence are still not fully explored.

Methods: In this study, fecal specimens of several snake species in Malaysia were examined for the presence of Sarcocystis by PCR of 185 rDNA sequence. Microscopy examination of the fecal specimens for sporocysts was not carried as it was difficult to determine the species of the infecting Sarcocystis.

Results: Of the 28 snake fecal specimens, 7 were positive by PCR. BLASTn and phylogenetic analyses of the amplified $18 \mathrm{~S}$ rDNA sequences revealed the snakes were infected with either S. nesbitti, S. singaporensis, S. zuoi or undefined Sarcocystis species.
\end{abstract}

Conclusion: This study is the first to report Sarcocystis infection in a cobra, and S. nesbitti in a reticulated python.

Keywords: Definitive host, Sarcocystis, Snake, 18S rDNA, Phylogenetic analysis

\section{Background}

Sarcocystis is an intracellular protozoan belonging to the family Sarcocystidae and is closely related to medically important protozoa, such as Toxoplasma gondii and Neospora caninum. Its life cycle involves intermediate and definitive hosts and is based on predator-prey relationships [1]. Asexual stages develop in intermediate hosts, ultimately resulting in the formation of intramuscular cysts (Sarcocysts). Following ingestion of tissue containing sarcocysts by a definitive host, the sexual stages of the life cycle are initiated in the intestine, producing oocysts that are excreted in feces [1]. Sarcocystosis is a zoonotic disease that is found mostly in tropical and sub-tropical countries, which usually affects wild and domestic animals, such as cows and pigs [2]. Notably, humans may serve as definitive hosts for Sarcocystis hominis and Sarcocystis suihominis after consuming raw, infected meat from cattle and pigs, respectively. However, humans can also be intermediate hosts for some Sarcocystis species of unknown origin. In such

\footnotetext{
* Correspondence: lauyeeling@um.edu.my

${ }^{\dagger}$ Equal contributors

'Department of Parasitology, Faculty of Medicine, University of Malaya, 50603 Kuala Lumpur, Malaysia

Full list of author information is available at the end of the article
}

cases, humans can be infected through food or drinks that are contaminated with feces containing sporocyst from infected animals. In fact, a study identified sarcocystosis antibodies in 20\% of Malaysians [3], and tissue autopsies showed 21 out of 100 individuals contained sarcocysts [4]. In December 2011, the surveillance program of the International Society of Travel Medicine and Centers for Disease Control and Prevention (CDC) reported an outbreak of acute muscular sarcocystosis, which involved 32 travellers to Tioman Island off the coast of peninsular Malaysia [5]; however, the Sarcocystis species involved was not identified.

Muscular sarcocystosis can be diagnosed through microscopic examination of histologic sections stained with hematoxylin and eosin. Nevertheless, technical variability in staining and tissue sectioning procedures might be anticipated [6]. Additionally, the ultrastructure of many species is inadequately described. Thus, definitive diagnosis of sarcocystosis requires identification of sporocysts in feces. However, the sporocysts of different species are similar in size and shape, making species identification almost impossible by microscopy. Therefore, sequencing of the small subunit ribosomal RNA (18S rRNA) gene was introduced as an ideal means for 
species-specific detection [7]. In fact, this gene contains hypervariable regions interspersed within highly conserved DNA sequences, making it ideal for differentiation between species. For this reason, the 18S rRNA gene has been frequently used in phylogenetic analyses of species within the Apicomplexa [8-14]. Moreover, the large number of $18 \mathrm{~S}$ rRNA gene sequences available for different Sarcocystis species should enable construction of an informative phylogenetic tree of the Sarcocystidae. Indeed, the utility of $18 \mathrm{~S}$ rRNA gene sequencing for differentiation of Sarcocystis species and for phylogenetic studies has been demonstrated by several researchers [15-18].

SP Kan and R Pathmanathan [19] have highlighted five well-defined (complete life cycle) Sarcocystis species in Malaysia. Notably, it was identified that three out of five of these Sarcocystis species (i.e., S. singaporensis, $S$. villivillosus, and S. zamani) circulate between pythons (definitive hosts) and rats (intermediate hosts) [20], indicating the high diversity of Sarcocystis species infecting snakes. During their research in Thailand, T Jakel, Y Khoprasert, I Sorger, D Kliemt, V Seehabutr, K Suasa-ard and S Hongnark [21] confirmed that Broghammerus/ Python reticulatus [22] served as a suitable definitive host for S. singaporensis and S. zamani. Furthermore, in other countries, P Daszak and A Cunningham [23] as well as
Šlapeta and his collaborators (2003) discovered Sarcocystis species parasitizing a bullsnake (Pituophis melanoleucus sayi) and African tree vipers (Atheris spp. and Bitis spp.), respectively.

Here, we have performed phylogenetic analyses based on sequencing of the 18S rRNA gene in order to determine evolutionary relationships between Sarcocystis species isolated from Malaysian snakes.

\section{Methods}

\section{Sample collection}

Fecal samples of snake were collected from Perak (Taiping Zoo and Pangkor Island), Kelantan (Kuala Kerai), Kedah (Langkawi Wildlife Park) and from isolated private snake owners (Sri Gombak and Cheras), Malaysia. A total of 28 snakes were caught, including 14 reticulated python (Broghammerus/Python reticulates), 3 Malayan Brown Pit Viper (Ovophis convictus), 2 King cobra (Ophiophagus hannah), 1 Monocled cobra (Naja kaouthia), 1 Wagler's keeled green pit viper (Tropidolae muswagleri), 1 Malayan keeled rat snake (Ptyas carinata), 1 Albino python (Python bivittatus), 1 Boa python (Python regius subspecies), 1 Ball python (Python regius), 1 Mangrove snake (Boiga dendrophila melanota), 1 Mexican black king snake (Lampropeltis getula nigrita) and 1 King snake (Lampropeltis sp.). The snakes

Table 1 Summary of Sarcocystis species found in infected snakes

\begin{tabular}{|c|c|c|c|c|c|c|c|}
\hline Snake taxa species & State & $\begin{array}{l}\text { Number } \\
\text { of snake }\end{array}$ & Clone name & $\begin{array}{l}\text { Sarcocystis } \\
\text { species }\end{array}$ & $\begin{array}{l}\text { Possible } \\
\text { definitive host }\end{array}$ & $\begin{array}{l}\text { Possible } \\
\text { intermediate host }\end{array}$ & References \\
\hline \multirow[t]{5}{*}{ Cobra Naja kaouthia } & \multirow[t]{5}{*}{ Kuala Kerai } & \multirow[t]{5}{*}{1} & \multirow[t]{5}{*}{ MAL-2, MAL-4 } & \multirow[t]{5}{*}{ S. nesbitti } & \multirow[t]{5}{*}{ Snake } & Monkeys & \multirow[t]{5}{*}[25,26]{} \\
\hline & & & & & & (Macaca mulatta) & \\
\hline & & & & & & (Macaca fascicularis) & \\
\hline & & & & & & (Cercocebus atys) & \\
\hline & & & & & & (Papio papionis) & \\
\hline \multirow{8}{*}{$\begin{array}{l}\text { Reticulated python } \\
\text { Braghammerus reticulatus } \\
\text { (Previously known as } \\
\text { Phyton reticulatus) }\end{array}$} & \multirow{8}{*}{$\begin{array}{l}\text { Langkawi } \\
\text { Wildlife Park }\end{array}$} & \multirow[t]{2}{*}{2} & \multirow[t]{2}{*}{ MAL-9, MAL-11 } & \multirow[t]{2}{*}{ S. singaporensis } & $\begin{array}{l}\text { Reticulated } \\
\text { python }\end{array}$ & \multirow[t]{2}{*}{$\begin{array}{l}\text { Genera Rattus and } \\
\text { Bandicota }\end{array}$} & \multirow[t]{2}{*}{ [21] } \\
\hline & & & & & $\begin{array}{l}\text { (Broghammerus } \\
\text { reticulatus) }\end{array}$ & & \\
\hline & & \multirow[t]{5}{*}{1} & \multirow[t]{5}{*}{ MAL-5, MAL-6, MAL-7 } & \multirow[t]{5}{*}{ S. nesbitti } & \multirow[t]{5}{*}{ Undefined } & Monkeys & \multirow[t]{5}{*}[25,26]{} \\
\hline & & & & & & (Macaca mulatta) & \\
\hline & & & & & & (Macaca fascicularis) & \\
\hline & & & & & & (Cercocebus atys) & \\
\hline & & & & & & (Papio papionis) & \\
\hline & & 1 & $\begin{array}{l}\text { MAL-8, MAL-10, MAL-12, } \\
\text { MAL-13, MAL-14 }\end{array}$ & Sarcocystis sp. & - & - & - \\
\hline \multirow[t]{2}{*}{$\begin{array}{l}\text { Malayan Brown Pit Viper } \\
\text { Ovophis convictus }\end{array}$} & \multirow[t]{2}{*}{ Pangkor Island } & \multirow[t]{2}{*}{1} & \multirow[t]{2}{*}{ MAL-17 to MAL-22 } & \multirow[t]{2}{*}{ S. singaporensis } & $\begin{array}{l}\text { Reticulated } \\
\text { python }\end{array}$ & \multirow[t]{2}{*}{$\begin{array}{l}\text { Genera Rattus and } \\
\text { Bandicota }\end{array}$} & \multirow[t]{2}{*}[21]{} \\
\hline & & & & & $\begin{array}{l}\text { (Broghammerus } \\
\text { reticulatus) }\end{array}$ & & \\
\hline \multirow{2}{*}{$\begin{array}{l}\text { Malayan Keeled rat snake } \\
\text { Ptyas carinata }\end{array}$} & \multirow[t]{2}{*}{ Kuala Kerai } & \multirow[t]{2}{*}{1} & \multirow[t]{2}{*}{ MAL-15, MAL-16 } & \multirow[t]{2}{*}{ S. zuoi } & King rat snakes & Norway rats & \multirow[t]{2}{*}{ [16] } \\
\hline & & & & & (Elaphe carinata) & (Rattus norvegicus) & \\
\hline
\end{tabular}


(See figure on previous page.)

Figure 1 Phylogenetic tree based on 18S rRNA sequences of Sarcocystis species. The tree is constructed using the Neighbour Joining method. The percentage of replicate trees in which the associated sequences clustered together in the bootstrap test (1000 replicates) are shown next to the branches [27]. The tree is drawn to scale, with branch lengths in the same units as those of the evolutionary distances used to infer the phylogenetic tree. The phylogenetic analysis was conducted using MEGA4 [24].

consumed similar diets such as rats and frogs. The fecal samples were stored in $2.5 \%$ potassium dichromate and kept at $4^{\circ} \mathrm{C}$ for further use. This research was carried out with the approval by the University Malaya Medical Ethics Committee (Ref no. 920.16).

\section{Sample processing and examination}

The preserved samples were examined under a microscope. Fecal samples were concentrated by formalinether concentration and filtered to remove the course debris followed by microscopic examination.

\section{DNA isolation}

Total DNA from fecal samples was isolated using the PowerSoil $^{\odot}$ DNA Isolation Kit (MO BIO Laboratories) according to the manufacturer's protocol. Briefly, $0.25 \mathrm{~g}$ of the fecal sample was lysed by adding the solution containing SDS (Solution C1). The non-DNA organic and inorganic materials in the lysed sample were removed by adding Solution C2 and Solution C3. Following centrifugation, the supernatant was mixed with high salt solution (Solution C4) and loaded into the Spin Filter to allow binding of DNA to the silica membrane. The bound DNA was cleaned with ethanol wash solution (Solution C5) and followed by elution of the DNA by using $30 \mu$ l elution buffer (Solution 6).

\section{Polymerase chain reaction}

The 18S rRNA gene was amplified by nested PCR, using primer 1 L (5'-CCATGCATGTCTAAGTATAAGC-3') and primer $1 \mathrm{H}$ ( $5^{\prime}$-TATCCCCATCACGATGCATAC- $\left.3^{\prime}\right)$ in the primary reaction, followed by primer $3 \mathrm{~L}\left(5^{\prime}\right.$ CTAGTGATTGGAATGATGGG-3') and primer $2 \mathrm{H}$ (5'-ACCTGTTATTGCCTCAAACTTC-3') in the secondary reaction [18]. Four $\mu \mathrm{l}$ of the DNA template was used in a $25 \mu \mathrm{l}$ PCR reaction, with the following reaction conditions: $35 \mathrm{mM}$ Tris- $\mathrm{HCl}, \mathrm{pH} 9.0,25 \mathrm{mM} \mathrm{KCl}$, $3.5 \mathrm{mM} \mathrm{MgCl} 2,5$ pmoles of each primer, $1 \mathrm{mM}$ dNTPs, and $1 \mathrm{U} \mathrm{Taq}$ polymerase (Promega). The PCR was performed as follows: $95^{\circ} \mathrm{C}$ for $2 \mathrm{~min}$, followed by 35 cycles of $94^{\circ} \mathrm{C}$ for $40 \mathrm{sec}, 50^{\circ} \mathrm{C}$ for $30 \mathrm{sec}, 72^{\circ} \mathrm{C}$ for $1.5 \mathrm{~min}$, followed by $72^{\circ} \mathrm{C}$ for $6 \mathrm{~min}$ [18]. The product was separated by agarose gel electrophoresis.

\section{Cloning and sequencing}

Amplicons were cloned using pGEM ${ }^{\bullet}-\mathrm{T}$ Vector System (Promega) and positive clones from each amplicon were sequenced in both directions by using M13 universal primers. Sequence analysis was performed using the BioEdit software.

\section{Nucleotide search and phylogenetic analysis}

Each 18S rRNA gene sequence was searched for match in the GenBank nucleotide database using the Basic Local Alignment Search Tool (BLASTn). Two to three sequences were chosen to represent each amplicon in phylogenetic analysis. The sequences were then compared and aligned with 18S rRNA gene sequences of Sarcocystis species available in GenBank. Multiple sequence alignment was carried out using ClustalW. A phylogenetic tree was constructed based on the $18 \mathrm{~S}$ rRNA gene sequences by Neighbor-Joining method (bootstrap $=1000$ ) available in MEGA4 [24]. The 18S rRNA gene sequence of Eimeria tennella was used as outgroup.

\section{Result}

In this study, 28 snake fecal samples were obtained but no oocyst/sarcocyst was found in the stools using microscopy. Seven snakes (25\%) were found to be positive for Sarcocystis $18 \mathrm{~S}$ rRNA by PCR. The 7 infected snakes included 4 reticulated pythons from Langkawi Wildlife Park; 1 Malayan brown pit viper from Pangkor; 1 Monocled cobra from Pangkor and 1 Malayan keeled rat snake from Kuala Kerai (Table 1). Amplicons from the PCR reaction were cloned into pGEM $^{-}-\mathrm{T}$ and sequenced. Twenty 18S rRNA sequences were obtained and each sequence was searched for match in the GenBank database using BLASTn. Once the species was determined, a phylogenetic tree was constructed based on these 20 sequences plus 34 other Sarcocystis 18S rRNA sequences (Figure 1). The phylogenetic tree shows two major clades (A, B) of Sarcocystis. Clade A is divided into two subclades (I, II). Subclade I consisted of species that infect ruminants. Subclade II is further divided into two groups, one consisting of species whose hosts are animals such as birds, opossum, treeshrew and lizard. The other group consisted of Sarcocystis species in which snakes (python, ratsnake, viper) are the definitive hosts, such as S. singaporensis and S. zuoi. Interestingly, clade B contains only one group. The members of this group, $S$. nesbittii and $S$. atheridis, use snakes (python, cobra, viper) as definitive hosts. The Sarcocystis detected in the snake fecal samples of our study are distributed in both clades $\mathrm{A}$ and $\mathrm{B}$. 


\section{Discussion}

This is the first report identifying infection of a monocled cobra (N. kaouthia) with Sarcocystis species. In addition, phylogenetic analysis based on sequencing of the 18S rRNA gene indicated that the Sarcocystis species isolated from the monocled cobra was most closely related to S. nesbitti, which was first discovered by [25] in rhesus monkey muscle. Mandour's work had been supported years later with the proof of light and transmission electron micrograph [26]. In 2011, Tian and his collaborators hypothesized that a snake might serve as the definitive host for $S$. nesbitti based on phylogenetic analyses [17]. This was due to the fact that $S$. nesbitti closely resembled certain Sarcocystis species that cycle between rodent intermediates and snakes (e.g., African tree vipers) [8]. Moreover, in our study, S. nesbitti was also found to infect reticulated pythons from Langkawi. Our findings have thus confirmed that snakes are likely to be the definitive host for $S$. nesbitti.

Four infected reticulated pythons were examined in this study: two with S. singaporensis, one with S. nesbitti, and the last with an unknown Sarcocystis species. Similarly in other studies, boid snake (Broghammerus/Python reticulatus) has shown to be the natural definitive host of S. singaporensis. S. singaporensis develops sexually in the intestine of the snake to produce sporocysts, which are released in the faces [20]. Suitable intermediate hosts for S. singaporensis include all of Rattus and Bandicota species as well as Nesokia indica [20,28-30]. Furthermore, S. singaporensis is endemic in Southeast Asia [31-34], and considered to be highly pathogenic. In fact, it can be lethal due to extensive development of schizonts in rat endothelial cells [28]. As a result, it could potentially be used as a biological agent for controlling wild rodent populations in non-native environments [35].

Previous studies have reported vipers to be the definitive hosts for a few species of Sarcocystis, including $S$. atheridis in Nitsche's bush viper (Atheris nitschei) [36], S. hoarensis in Bitis arientans [37], and Sarcocystis muriviperae in Palestine viper (Vipera palestinae) [37]. In the present study, Malayan brown pit viper was infected with $S$. singaporensis.

S. zuoi was detected in Malayan keeled rat snake. Indeed, S. zuoi is commonly found in Norway rats (Rattus norvegicus), and transmission experiments carried out in China have indicated that the king rat snake is the definitive host of S. zuoi [16].

So far, phylogenetic relationships among the majority of analyzed Sarcocystis species have suggested their coevolution with final rather than intermediate hosts [8]. Our results are consistent with this notion because all of the Sarcocystis species that we have isolated from snakes are related to S. nesbitti, S. singaporensis, and
S. zuoi, which are Sarcocystis species using snakes as definitive hosts.

\section{Conclusion}

We have demonstrated a high (25\%) prevalence of Sarcocystis infection in snake populations in peninsular Malaysia. Taken together, we have identified snakes infected by $S$. nesbitti, S. singaporensis, S. zuoi, and some undefined species. These findings contribute to our phylogenetic understanding of the Sarcocystidae and provide valuable information to build upon for future research.

\section{Competing interests}

The authors have no financial or personal relationship with other people or organizations that could inappropriately influence or bias this paper.

\section{Authors' contributions}

PYC carried out the experiment, YLL contributed most on manuscript writing. YHN helped in manuscript writing and editing, MYF helped on phylogenetic tree construction. RM and AA provided opinions and suggestions about this manuscript while SV supplied useful information about the snakes in South East Asia. All authors read and approved the final version of the manuscript.

\section{Acknowledgments}

This study was supported by UM High Impact Research Grant UM-MOHE (UM.C/HIR/MOHE/MED/18) from the Ministry of Higher Education Malaysia and UMRG (Grant no. RP011-2012) from University of Malaya. The authors highly appreciate the indispensable contribution of the zoos and pet owners for contributing samples in this research.

\section{Author details}

${ }^{1}$ Department of Parasitology, Faculty of Medicine, University of Malaya, 50603 Kuala Lumpur, Malaysia. ${ }^{2}$ Faculty of Pharmacy, Universiti Teknologi MARA, 43200 Puncak Alam, Selangor, Malaysia.

Received: 5 July 2013 Accepted: 26 August 2013

Published: 9 September 2013

\section{References}

1. Fayer R: Sarcocystis spp. in human infections. Clin Microbiol Rev 2004, 17(4):894-902. table of contents.

2. Wong KT, Pathmanathan R: Human muscular sarcocystosis in Malaysia. Trop Geogr Med 1993, 45(4):191.

3. Thomas V, Dissanaike AS: Antibodies to Sarcocystis in Malaysians. Trans $R$ Soc Trop Med Hyg 1978, 72(3):303-306.

4. Wong KT, Pathmanathan R: High prevalence of human skeletal muscle sarcocystosis in south-east Asia. Trans $R$ Soc Trop Med Hyg 1992, 86(6):631-632

5. Sonnenburg F, Cramer J, Freedman D, Plier A, Esposito D, Sotir M, Lankau E: Notes from the field: acute muscular sarcocystosis among returning travelers-Tioman Island, Malaysia, 2011. Morb Mortal Wkly Rep 2012, 61(2):37-38.

6. Lindsay DS, Blagburn BL, Braund KG: Sarcocystis spp. and sarcocystosis. Br Med J 1995, 5(3):249-254.

7. Tenter AM: Current research on Sarcocystis species of domestic animals. Int J Parasitol 1995, 25(11):1311-1330.

8. Dolezel D, Koudela B, Jirku M, Hypsa V, Obornik M, Votypka J, Modry D, Slapeta JR, Lukes J: Phylogenetic analysis of Sarcocystis spp. of mammals and reptiles supports the coevolution of Sarcocystis spp. with their final hosts. Int J Parasitol 1999, 29(5):795-798.

9. Elsheikha HM, Lacher DW, Mansfield LS: Phylogenetic relationships of Sarcocystis neurona of horses and opossums to other cyst-forming coccidia deduced from SSU rRNA gene sequences. Parasitol Res 2005, 97(5):345-357 
10. Holmdahl OJ, Morrison DA, Ellis JT, Huong LT: Evolution of ruminant Sarcocystis (Sporozoa) parasites based on small subunit rDNA sequences. Mol Phylogenet Evol 1999, 11(1):27-37.

11. Jeffries AC, Schnitzler B, Heydorn AO, Johnson AM, Tenter AM: Identification of synapomorphic characters in the genus Sarcocystis based on 18S rDNA sequence comparison. J Eukaryot Microbiol 1997, 44(5):388-392

12. Morrison DA, Bornstein S, Thebo P, Wernery U, Kinne J, Mattsson JG: The current status of the small subunit rRNA phylogeny of the coccidia (Sporozoa). Int J Parasitol 2004, 34(4):501-514.

13. Slapeta JR, Kyselova I, Richardson AO, Modry D, Lukes J: Phylogeny and sequence variability of the Sarcocystis singaporensis Zaman and Colley, (1975) 1976 ssrDNA. Parasitol Res 2002, 88(9):810-815.

14. Slapeta JR, Modry D, Votypka J, Jirku M, Lukes J, Koudela B: Evolutionary relationships among cyst-forming coccidia Sarcocystis spp. (Alveolata: Apicomplexa: Coccidea) in endemic African tree vipers and perspective for evolution of heteroxenous life cycle. Mol Phylogenet Evol 2003, 27(3):464-475

15. Dahlgren SS, Gouveia-Oliveira R, Gjerde B: Phylogenetic relationships between Sarcocystis species from reindeer and other Sarcocystidae deduced from ssu rRNA gene sequences. Vet Parasito/ 2008, 151(1):27-35.

16. Hu JJ, Meng Y, Guo YM, Liao JY, Song JL: Completion of the life cycle of Sarcocystis zuoi, a parasite from the Norway rat, Rattus norvegicus. J Parasitol 2012, 98(3):550-553.

17. Tian M, Chen Y, Wu L, Rosenthal BM, Liu X, He Y, Dunams DB, Cui L, Yang Z: Phylogenetic analysis of Sarcocystis nesbitti (Coccidia: Sarcocystidae) suggests a snake as its probable definitive host. Vet Parasitol 2012, 183(3-4):373-376.

18. Yang ZQ, Zuo YX, Ding B, Chen XW, Luo J, Zhang YP: Identification of Sarcocystis hominis-like (Protozoa: Sarcocystidae) cyst in water buffalo (Bubalus bubalis) based on 18S rRNA gene sequences. J Parasitol 2001, 87(4):934-937

19. Kan SP, Pathmanathan R: Review of sarcocystosis in Malaysia. Southeast Asian J Trop Med Public Health 1991, 22(Suppl):129-134.

20. Beaver PC, Maleckar JR: Sarcocystis singaporensis Zaman and Colley, (1975) 1976, Sarcocystis villivilliso sp. n., and Sarcocystis zamani sp. n. development, morphology, and persistence in the laboratory rat, Rattus norvegicus. J Parasitol 1981, 67(2):241-256.

21. Jakel T, Khoprasert Y, Sorger I, Kliemt D, Seehabutr V, Suasa-ard K, Hongnark S: Sarcosporidiasis in rodents from Thailand. J Wildl Dis 1997, 33(4):860-867.

22. Das I: A Field Guide to the Reptiles of South-East Asia. UK: New Holland Publisher; 2010.

23. Daszak $P$, Cunningham A: A report of intestinal sarcocystosis in the bullsnake (Pituophis melanoleucus sayi) and a re-evaluation of Sarcocystis sp. from snakes of the genus Pituophis. J Wildl Dis 1995, 31(3):400-403

24. Tamura K, Dudley J, Nei M, Kumar S: MEGA4: Molecular Evolutionary Genetics Analysis (MEGA) software version 4.0. Mol Biol Evol 2007, 24(8):1596-1599.

25. Mandour AM: Sarcocystis nesbitti n. sp. from the rhesus monkey. J Protozool 1969, 16(2):353-354

26. Yang ZQ, Wei CG, Zen JS, Song JL, Zuo YX, He YS, Zhang HF, Attwood SW, Chen XW, Yang GC, et al: A taxonomic re-appraisal of Sarcocystis nesbitti (Protozoa: Sarcocystidae) from the monkey Macaca fascicularis in Yunnan, PR China. Parasitol Int 2005, 54(1):75-81.

27. Felsenstein J: Confidence limits on phylogenies: an approach using the bootstrap. Evolution 1985, 39(4):783-791.

28. Brehm H, Frank W: [The life-history of Sarcocystis singaporensis Zaman and Colley, 1976 in the definitive and intermediate host (author's transl)]. Z Parasitenkd 1980, 62(1):15-30

29. Hafner U, Frank W: Host specificity and host range of the genus Sarcocystis in three snake-rodent life cycles. Zentralbl Bakteriol Mikrobiol Hyg A 1984, 256(3):296-299.

30. Zaman V, Colley FC: Light and electron microscopic observations of the life cycle of Sarcocystis orientalis sp. $\mathrm{n}$. in the rat (Rattus norvegicus) and the Malaysian reticulated python (Python reticulatus). Z Parasitenkd 1975, 47(3):169-185

31. Kan SP: Ultrastructure of the cyst wall of Sarcocystis spp. from some rodents in Malaysia. Int J Parasitol 1979, 9(5):475-480.
32. Kan SP, Dissanaike AS: Ultrastructure of Sarcocystis sp. from the Malaysian house rat, Rattus rattus diardii. Z Parasitenkd 1977, 52(3):219-227.

33. Lai PF: Developmental stages of Sarcocystis fusiformis (Railliet, 1897) and Sarcocystis sp., of the water buffalo, in the small intestines of cats and dogs respectively. Southeast Asian J Trop Med Public Health 1977, 8(3):417-419.

34. O'Donoghue PJ, Watts CH, Dixon BR: Ultrastructure of Sarcocystis spp. (Protozoa: Apicomplexa) in rodents from North Sulawesi and West Java, Indonesia. J Wildl Dis 1987, 23(2):225-232.

35. Jakel T, Burgstaller $H$, Frank W: Sarcocystis singaporensis: studies on host specificity, pathogenicity, and potential use as a biocontrol agent of wild rats. J Parasitol 1996, 82(2):280-287

36. Slapeta JR, Modry D, Koudela B: Sarcocystis atheridis sp. nov., a new sarcosporidian coccidium from Nitsche's bush viper, Atheris nitschei Tornier, 1902, from Uganda. Parasitol Res 1999, 85(8-9):758-764.

37. Matuschka FR, Heydorn AO, Mehlhorn H, Abd-Al-Aal Z, Diesing L, Biehler A: Experimental transmission of Sarcocystis muriviperae n. sp. to laboratory mice by sporocysts from the Palestinian viper (Vipera palaestinae): a light and electron microscope study. Parasitol Res 1987, 73(1):33-40.

doi:10.1186/1756-3305-6-257

Cite this article as: Lau et al:: Genetic assemblage of Sarcocystis spp. in Malaysian snakes. Parasites \& Vectors 2013 6:257

\section{Submit your next manuscript to BioMed Central and take full advantage of:}

- Convenient online submission

- Thorough peer review

- No space constraints or color figure charges

- Immediate publication on acceptance

- Inclusion in PubMed, CAS, Scopus and Google Scholar

- Research which is freely available for redistribution
C Biomed Central 